\title{
Pregabalin, celecoxib, and their combination for treatment of chronic low-back pain
}

\author{
Carlo Luca Romanò • Delia Romanò • \\ Cristina Bonora $\cdot$ Giuseppe Mineo
}

Received: 27 August 2009/Accepted: 3 November 2009/Published online: 18 November 2009

(C) Springer-Verlag 2009

\begin{abstract}
Background The efficacy and safety of the association of celecoxib [a selective cyclooxygenase-2 (COX-2) inhibitor] and pregabalin (commonly used to control neuropathic pain), compared with monotherapy of each, were evaluated for the treatment of chronic low-back pain, a condition known to be due to neuropathic as well as nociceptive pain mechanisms.

Materials and methods In this prospective randomized trial, 36 patients received three consecutive 4-week treatment regimes, randomly assigned: celecoxib plus placebo, pregabalin plus placebo, and celecoxib plus pregabalin. All patients were assessed by using a visual analogue scale (VAS, 0-100 mm) and the Leeds Assessment of Neuropathic Symptoms and Signs (LANSS) pain scale by an investigator blinded to the administered pharmacological treatment.

Results Celecoxib and pregabalin were effective in reducing low-back pain when patients were pooled according to LANSS score. The association of celecoxib and pregabalin was more effective than either monotherapy in a mixed population of patients with chronic low-back pain and when data were pooled according to LANSS score. Adverse effects of drug association and monotherapies were similar, with reduced drug consumption in the combined therapy.
\end{abstract}

C. L. Romanò $(\varangle) \cdot$ D. Romanò · C. Bonora Istituto Ortopedico I.R.C.C.S. Galeazzi, Via Riccardo Galeazzi, 4, 20166 Milan, Italy

e-mail: carlo.romano@grupposandonato.it

G. Mineo

Istituto Ortopedico I.R.C.C.S. Galeazzi, Università degli Studi di Milano, Via Riccardo Galeazzi, 4, 20166 Milan, Italy
Conclusions Combination of celecoxib and pregabalin is more effective than monotherapy for chronic low-back pain, with similar adverse effects.

Keywords Pregabalin - Celecoxib - Low-back pain · Polypharmacotherapy

\section{Introduction}

Low-back pain is the fifth most common reason for all physician visits in the USA [1, 2]. Many patients have selflimited episodes of acute low-back pain and do not seek medical care [3]. Among those who do seek medical care, pain, disability, and return to work typically improve rapidly in the first month [4]. However, up to one-third of patients report persistent back pain of at least moderate intensity 1 year after an acute episode $[5,6]$.

Successful treatment of pain depends on identification of the involved mechanism and use of appropriate therapeutic approaches.

Woolf et al. [7] proposed that pain symptoms and syndromes should be classified into two broad mechanismbased pain categories: tissue-injury pain (nociceptive) or nervous-system-injury pain (neuropathic). Chronic lowback pain (LBP) has been shown to be the result of neuropathic as well as nociceptive pain mechanisms [8-11]. Based on this evidence, it has been suggested that antidepressants and/or anticonvulsants in combination with either opioids, traditional nonsteroidal anti-inflammatory drugs or muscle relaxants could be useful in the treatment of this condition [11-13].

Even if there is increasing knowledge that different mechanisms of pain require appropriate treatments and often polypharmacotherapy, and although drug combination is 
frequently empirically adopted in clinical practice, prospective studies concerning the relative efficacy and safety of polypharmacotherapy compared with monotherapy are still relatively few [14-20].

Among the most commonly used agents to control neuropathic pain is pregabalin, which has been validated in different clinical settings [14, 21-23], while celecoxib is a selective COX-2 inhibitor that has been proved to be effective in the treatment of different pain models that are considered predominantly of nociceptive origin [24-26].

Aim of this prospective, single-blind, randomized study was to compare the safety and efficacy of the association of celecoxib and pregabalin with monotherapy of each for treatment of chronic low-back pain in a mixed population of patients affected by chronic low-back pain and then to interpret the results by pooling the same patients according to Leeds Assessment of Neuropathic Symptoms and Signs (LANSS) pain scale [27, 28].

\section{Methods}

In this 12-week, double-blind, prospective study, performed at our institution from 2006 to 2008, we compared the efficacy and tolerability of the combination of a selective COX-2 inhibitor, anti-inflammatory drug, celecoxib and an antineuropathic drug, pregabalin, versus either celecoxib or pregabalin plus placebo, in the treatment of chronic LBP due to disc prolapse, lumbar spondylosis, and/or spinal stenosis.

The study was performed in accordance with the ethical standards of the 1964 Declaration of Helsinki as revised in 2000 and approved by the Institutional Review Board. Informed consent was obtained from each subject at recruitment.

\section{Patient population}

Of the originally enrolled 42 patients, 36 completed the study, 16 men and 20 women (Table 1).

Inclusion criteria were the following:

- Chronic low-back pain (symptoms duration: $>6$ months, mean: $13 \pm 6$ months) due to disc prolapse, lumbar spondylosis, and/or spinal stenosis;

- Minimum VAS at recruitment: $>40 \mathrm{~mm}$

- Age: $>18$ years, $<75$ years;

- Informed consent.

Exclusion criteria:

- Previous back surgery;

- Diabetes;

- Neurological disease;
Table 1 Demographic and anamnestic patient data $(n=36)$

\begin{tabular}{ll}
\hline Patient characteristics & Total number \\
\hline Sex & 16 \\
Male & 20 \\
Female & \\
Race & 33 \\
White & 1 \\
Black & 2 \\
Asian & $53 \pm 16$ \\
Mean age (years) & $71 \pm 14$ \\
Mean weight (kg) & \\
Smoking habits & 13 \\
Smoker & 5 \\
Ex-smoker & 18 \\
Nonsmoker & 30 \\
Previous use of medications & \\
Causes of LBP (may be associated) & 17 \\
Disc prolapse & 14 \\
Lumbar spondylosis & 7 \\
Spinal canal stenosis & \\
\hline
\end{tabular}

- Cardio-renal disease;

- History of gastric ulcers or intestinal bleeding;

- Known allergy to the drugs under study;

- Alcohol or drug abuse.

Once the patient was found eligible to participate in the study, informed consent was obtained.

Assessment

Primary outcomes was mean pain reduction following different treatments regimes. Secondary outcomes were adverse effects due to the treatments under study.

Before starting treatment, demographic and anthropometric data, as well as a medical history, were collected. All patients were assessed by visual analogue scale $(100 \mathrm{~mm})$, LANSS, and radiographically.

Visual analogue scale was evaluated at patient recruitment and before and after any 4-week treatment period by an investigator blinded to the administered pharmacological treatment.

The LANSS pain scale consisted of a two-sided A4 sheet and was designed to be used in interview format during a single session. The interview, performed at recruitment, consisted of the clinician reading the questionnaire and asking the patient whether the description matched their pain characteristics in the preceding week. This session was followed by a bedside examination for any sensory dysfunction and specifically for allodynia and for altered pinprick threshold (PPT). Allodynia was judged 
to be present when pain was elicited by the gentle stroke of a piece of cotton over the painful area in comparison with a nonpainful area. PPT was determined by comparing the response to a 23 -gauge needle mounted inside a $2-\mathrm{mL}$ syringe barrel placed onto the skin in nonpainful and then painful areas several times. PPT was defined as a sharp sensation in relation to gentle needle placement in a painful area. According to the LANSS pain scale, the frequency of each item of the five pain symptoms, as well as the two sensory examination items, was calculated for every patient. Dysesthesia and autonomic dysfunction were given a score of 5 each, if present. Evoked pain was given a score of 3. Paroxysmal pain was given a score of 2. Thermal pain was given a score of 1 . For testing sensory dysfunction, allodynia, if found, was given a score of 5 , and altered PPT was given a score of 3 . Accordingly, the total summed scores had a maximum of 24 points. Patients with a score less than 12 were considered unlikely to have neuropathic low-back pain, whereas patients with a score of 12 or more were considered to have a neuropathic element that contributed to their low-back pain. Neither psychological status nor social class of patients was included in the study.

\section{Treatment regime}

After a discontinuation period of at least 7 days from any previous analgesic treatment and between treatments, each patient received the following three consecutive treatments regimes:

- Celecoxib (approximately 3-6 mg/kg/die) + placebo;

- Pregabalin (approximately $1 \mathrm{mg} / \mathrm{kg} / \mathrm{die}$ the first week and then $2-4 \mathrm{mg} / \mathrm{kg} / \mathrm{die})+$ placebo;

- Celecoxib (approximately 3-6 $\mathrm{mg} / \mathrm{kg} / \mathrm{die}$ ) plus pregabalin (approximately $1 \mathrm{mg} / \mathrm{kg} / \mathrm{die}$ the first week and then $2-4 \mathrm{mg} / \mathrm{kg} / \mathrm{die})$.

Each treatment lasted 4 weeks, with 1-week discontinuation between treatments (Table 2). The sequence of treatments in each patient was randomly assigned as follows, based on consecutive recruitment order: first patient received celecoxib + placebo, pregabalin + placebo, celecoxib + pregabalin; second patient received pregabalin + placebo, celecoxib + pregabalin, celecoxib + placebo; third patient received celecoxib + pregabalin, celecoxib + placebo, pregabalin + placebo; and so on.

Concomitant use of antidepressants and/or anticonvulsants, opioids, nonsteroidal anti-inflammatory drugs or muscle relaxants was not permitted during the 12-week study.

\section{Statistical analysis}

Descriptive statistics were determined by calculation of the mean and standard deviation $( \pm \mathrm{SD})$. Statistical analysis was performed with Student's $t$ test.

Stratification on the basis of LANSS pain scale score (with a score of 12 or more as the cutoff point) was done for intergroup comparison.

Results throughout the text, tables, and figures are presented as mean \pm SD unless otherwise specified, and statistical significance was defined as $P<0.05$. Sample size was chosen according to a minimum expected difference in pain control of different treatment regimes of $10 \%$.

\section{Results}

Of the 42 patients initially recruited for the study, 6 decided to discontinue the treatment or did not present themselves at the programmed controls and were then excluded from data analysis. Among these six patients, four (one taking celecoxib alone, one taking pregabalin alone, two taking pregabalin + celecoxib) refused to continue the treatment within the first 2 weeks due to reported epigastralgia and/or nausea, one patient was lost to follow-up after 22 days due to logistical problems (work travelling outside Italy), and one due to intercurrent trauma (car accident). All presented data will be referred to the remaining 36 patients who completed the study and were available at follow-up.

Table 2 Experimental setup

\begin{tabular}{|c|c|c|c|c|}
\hline Week & Action & Cohort $1(N=12)$ & Cohort $2(N=12)$ & Cohort $3(N=12)$ \\
\hline 0 & \multicolumn{4}{|c|}{ Patient's recruitment/assessment/randomization. Any treatment discontinuation } \\
\hline 1 & VAS assessment & Starts treatment $\mathrm{C}$ & Starts treatment $\mathrm{C}+\mathrm{P}$ & Starts treatment $\mathrm{P}$ \\
\hline 5 & \multicolumn{4}{|c|}{ Treatment discontinuation and VAS assessment } \\
\hline 6 & VAS assessment & Starts treatment $\mathrm{P}$ & Starts treatment $\mathrm{C}$ & Starts treatment $\mathrm{C}+\mathrm{P}$ \\
\hline 10 & \multicolumn{4}{|c|}{ Treatment discontinuation and VAS assessment } \\
\hline 11 & VAS assessment & Starts treatment $\mathrm{P}+\mathrm{C}$ & Starts treatment $\mathrm{P}$ & Starts treatment $\mathrm{C}$ \\
\hline 15 & \multicolumn{4}{|c|}{ Treatment discontinuation and VAS assessment } \\
\hline
\end{tabular}

$C$ celecoxib + placebo, $P$ pregabalin + placebo, $C+P$ celecoxib + pregabalin 
Table 3 Self-reported VAS before and after each 4-week treatment regime

\begin{tabular}{|c|c|c|c|c|c|c|c|}
\hline & \multicolumn{2}{|c|}{ Pretreatment } & \multicolumn{2}{|c|}{$\begin{array}{l}\text { End of } \\
\text { 4-week } \\
\text { treatment }\end{array}$} & \multirow{2}{*}{$\begin{array}{l}P \text { value } \\
\text { (end of treatment } \\
\text { versus } \\
\text { pretreatment) }\end{array}$} & \multirow{2}{*}{$\begin{array}{l}P \text { value } \\
\text { (drug combination } \\
\text { versus } \\
\text { celecoxib + placebo) }\end{array}$} & \multirow{2}{*}{$\begin{array}{l}P \text { value } \\
\text { (drug combination } \\
\text { versus } \\
\text { pregabalin }+ \text { placebo) }\end{array}$} \\
\hline & Mean & SD & Mean & SD & & & \\
\hline $\begin{array}{l}\text { Celecoxib + placebo (all patients, } \\
N=36)\end{array}$ & 45.1 & 13.1 & 39.5 & 12.2 & 0.06 & & \\
\hline $\begin{array}{l}\text { Celecoxib }+ \text { placebo }(\text { LANSS }<12 \text {, } \\
\quad N=20)\end{array}$ & 43.8 & 12.9 & 32.5 & 15.5 & 0.01 & & \\
\hline $\begin{array}{l}\text { Celecoxib + placebo (LANSS }>12 \\
\quad N=16)\end{array}$ & 46.8 & 13.6 & 45.7 & 14.3 & 0.8 & & \\
\hline Pregabalin + placebo $(N=36)$ & 48.1 & 14.2 & 43.1 & 13.5 & 0.12 & & \\
\hline $\begin{array}{l}\text { Pregabalin }+ \text { placebo }(\text { LANSS }<12, \\
\quad N=20 \text { ) }\end{array}$ & 49.4 & 13.2 & 50.7 & 13.8 & 0.76 & & \\
\hline $\begin{array}{l}\text { Pregabalin }+ \text { placebo (LANSS }>12 \text {, } \\
\quad N=16)\end{array}$ & 47.2 & 15.0 & 36.3 & 12.7 & 0.03 & & \\
\hline $\begin{array}{l}\text { Celecoxib }+ \text { pregabalin (all patients, } \\
N=36 \text { ) }\end{array}$ & 46.3 & 13.8 & 28.6 & 15.1 & 0.0001 & 0.001 & 0.0001 \\
\hline $\begin{array}{l}\text { Celecoxib }+ \text { pregabalin }(\text { LANSS }<12 \text {, } \\
N=20)\end{array}$ & 45.1 & 14.2 & 32.9 & 13.9 & 0.009 & 0.9 & 0.0002 \\
\hline $\begin{array}{l}\text { Celecoxib + pregabalin }(\text { LANSS }>12 \\
\quad N=16)\end{array}$ & 47.9 & 15.2 & 23.1 & 14.6 & 0.0001 & 0.0001 & 0.01 \\
\hline
\end{tabular}

Bold values indicate $P<0.05$

Of 36 patients, 20 had LANSS pain scale score $<12$, while the remaining 16/36 were rated $>12$.

Table 3 summarizes mean \pm standard deviation of recorded VAS immediately prior to the beginning of each treatment regime and after the 4-week treatment period. According to the statistical analysis of data, also provided in the same table, celecoxib + placebo and pregabalin + placebo did produce a statistically significant reduction of reported pain, in patients with LANSS score $<12$
$(P=0.01)$ and in patients with LANSS score $>12$ $(P=0.03)$, but not in the general population of patients studied. On the contrary, the association pregabalin + celecoxib resulted in a statistically significant reduction of self-reported pain when considering either all the recruited patients or the subpopulations divided according to LANSS score. The drug combination also proved more effective that pregabalin alone and more effective than celecoxib alone, except for patients with LANSS score $<12$.

\section{Mean V.A.S. reduction after treatment}

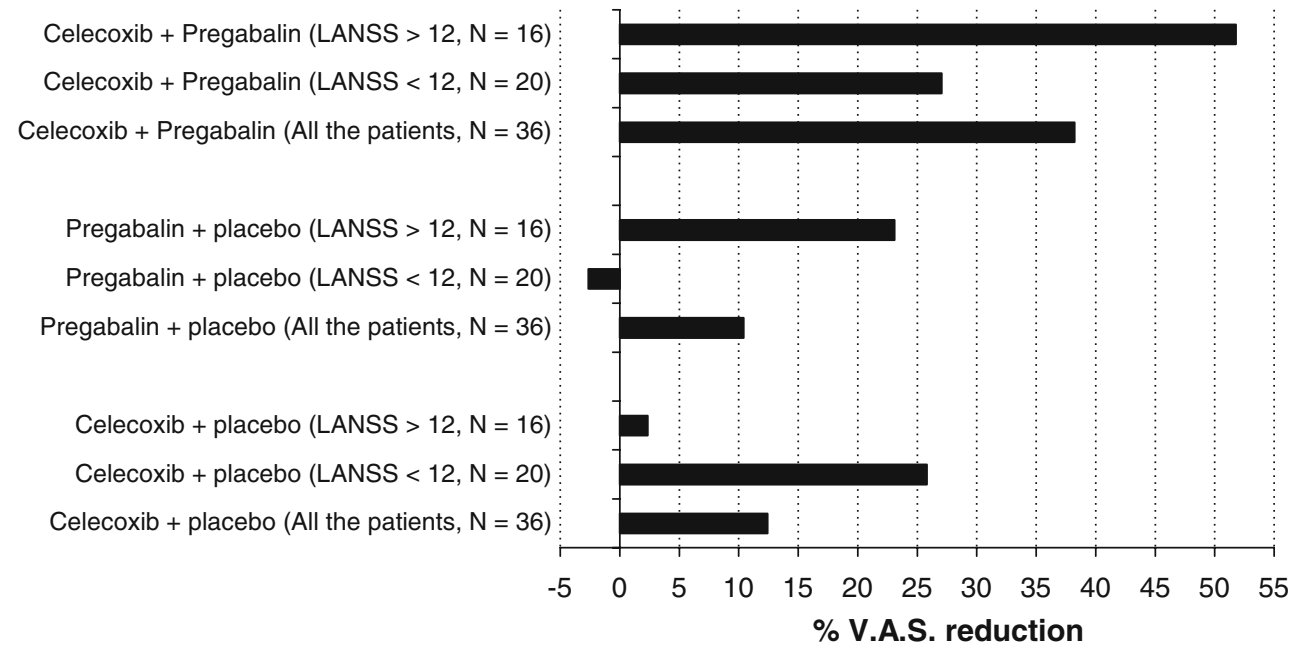

Fig. 1 Percentage pain reduction at the end of each 4-week treatment regime: mean VAS at the end of treatment/mean pretreatment VAS 
Figure 1 summarizes the percentage pain reduction following the different treatment regimes. When all patients were considered, celecoxib alone provided $12.4 \%$ pain reduction, pregabalin alone $10.4 \%$, and their combination $38.2 \%$. The largest pain reduction $(51.8 \%)$ was observed with the association pregabalin + celecoxib in patients with LANSS score $>12$.

\section{Drugs consumption}

The dosage of each drug was established at the beginning of each treatment period on the basis of each patient weight, but it could be modified during the treatment course by the physician, according to the pain and sideeffects reported by the patients. Overall drug consumption by any single patient was tracked. During celecoxib + placebo treatment, mean celecoxib consumption was $4.12 \pm 0.93 \mathrm{mg} / \mathrm{kg} / \mathrm{die}$; during pregabalin + placebo treatment it was $2.12 \pm 0.69 \mathrm{mg} / \mathrm{kg} / \mathrm{die}$; and during celecoxib + pregabalin treatment it was $3.75 \pm 0.86$ and $1.78 \pm 0.64 \mathrm{mg} / \mathrm{kg} / \mathrm{die}$, respectively. The difference of pregabalin and celecoxib consumption, when used in association, compared with monotherapies, was statistically significant for pregabalin $(P<0.05)$ but not for celecoxib $(P=0.09)$.

\section{Adverse effects}

Of the initially recruited $42,4(9 \%)$ discontinued treatment early due to side-effects and were not considered for further analysis of results. Of the remaining 36 patients, sideeffects were recorded in $16(44.4 \%)$ patients but did not require treatment discontinuation. Four had epigastralgia and nausea during celecoxib + placebo treatment, five reported nausea or dizziness after pregabalin + placebo, and seven experienced similar symptoms during treatment with celecoxib plus pregabalin.

\section{Discussion}

Nonsteroidal anti-inflammatory drugs (NSAIDs) are the most frequently prescribed medications worldwide and are widely used for patients with low-back pain. Selective COX-2 inhibitors are currently available and used for patients with low-back pain. A recently published systematic Cochrane review of randomized controlled trials has shown the efficacy of NSAIDs and COX-2 inhibitors in the treatment of nonspecific low-back pain. In 65 trials (total number of patients $=11,237$ ) statistically significant effects were found in favor of NSAIDs compared with placebo, but at the cost of statistically significant more side-effects. COX-2 NSAIDs had statistically significantly fewer side-effects than traditional NSAIDs [29].

Pregabalin is a ligand for the alpha-2-delta subunit of voltage-gated calcium channels with anticonvulsant, analgesic, and anxiolytic properties. It has predictable absorption across the gastrointestinal tract, is neither metabolized nor protein bound, and has minimal drug-drug interactions. Pregabalin has been widely studied for the treatment of neuropathic pain and was shown in prospective randomized clinical trials to be effective for postherpetic neuralgia and painful diabetic peripheral neuropathy, with approximately $50 \%$ responder rates. Pregabalin is also usually well tolerated in most patients, with infrequent severe adverse effects [30]. It has also been proved to be effective in other painful conditions, such as fibromyalgia [31, 32].

Pregabalin and its older companion, gabapentin, have already been successfully used in combination with other analgesic drugs to improve pain control. Gilron et al. [16] first reported on the efficacy and safety of a combination of gabapentin and morphine compared with that of each as a single agent in patients with painful diabetic neuropathy or postherpetic neuralgia. In 41 patients who completed the trial, gabapentin-morphine combination showed significantly better pain control $(P<0.05)$ versus placebo, gabapentin, and morphine. The group from the Ospedale Tor Vergata in Rome more recently published the Multicenter Italian Study, which compared the efficacy, safety, and quality of life of combination therapy with controlledrelease $(\mathrm{CR})$ oxycodone plus pregabalin versus monotherapy in patients with neuropathic pain [33]. This study showed in 409 patients that the combination of CR oxycodone plus pregabalin and CR oxycodone monotherapy were both more effective for alleviating neuropathic pain than was pregabalin monotherapy (reduction in an 11-point numerical rating scale of $80 \%, 76 \%$, and $46 \%$, respectively; $P=0.003$ ). Extremely significantly greater improvements from baseline in quality of life were reported with combination therapy than with monotherapy $(P=0.0009)$, and combination therapy also allowed dose reduction of both agents $(22 \%$ for $\mathrm{CR}$ oxycodone and $51 \%$ for pregabalin) compared with dosages of the respective monotherapies.

Other studies compared the efficacy of pregabalin or gabapentin in combination with different analgesic agents for postoperative pain. Gilron et al. [15] demonstrated, in a placebo-controlled randomized clinical trial on pain after abdominal hysterectomy, that perioperative administration of a combination of gabapentin and rofecoxib was significantly superior $(P<0.05)$ over monotherapy, with similar adverse effects, except sedation which was more frequent with gabapentin alone. The association of gabapentin with celecoxib was found by Parsa and co-workers $[18]$ to be significantly superior $(P<0.001)$ in 
reducing postoperative pain and opioid requirements than celecoxib alone in patients undergoing bilateral subpectoral breast augmentation.

Recently the association of pregabalin and of buprenorphine TDS and pregabalin in the treatment of low-back pain has been described [19]. In 22 patients buprenorphine provided a meaningful pain reduction (VAS $82.75 \pm 15$ versus $138.25 \pm 5, P<0.01$ ), but the association of low doses of pregabalin allowed a further reduction of the VAS $(P<0.01)$.

Michael Bennett in 2001 [27] introduced the Leeds Assessment of Neuropathic Symptoms and Signs (LANSS) pain scale. The LANSS has subsequently been tested and validated in several settings, with sensitivity and specificity ranging from $82 \%$ to $91 \%$ and $80 \%$ to $94 \%$, respectively, compared with clinical diagnosis [34]. After Baron and Binder [8] first introduced in 2004 the concept of mixed pain for sciatica, studies were published that confirmed the participation of nociceptive as well as neuropathic mechanisms of low-back pain. Kaki et al. [11] applied the LANSS pain scale in a total of 1,169 patients from 117 centers; 639 patients $(54.7 \%)$ had scores of 12 points or more, which suggested a neuropathic type of pain, and 530 patients $(45.3 \%)$ had scores of less than 12, which suggested a nociceptive type of pain. These authors concluded that neuropathic pain is a major contributor to chronic lowback pain and that the LANSS pain scale is a useful tool to distinguish patients with neuropathic pain from those with nociceptive pain.

To our knowledge, this is the first report of the efficacy of both celecoxib and pregabalin for the treatment of chronic low-back pain. The rate of treatment discontinuation $(4 / 42,9 \%)$, falls well within that reported for both drugs under study [14, 21-26]. We could also show that the relative efficacy of either monotherapy seems to correlate well with the outcome of the LANSS score and that combination of celecoxib and pregabalin proved to be superior to either single agent, with comparable sideeffects and reduced mean consumption of any single drug (calculated as mean administered dosage per patient weight).

Conflict of interest statement The authors declare that they have no conflict of interest related to the publication of this manuscript.

\section{References}

1. Deyo RA, Mirza SK, Martin BI (2006) Back pain prevalence, visit rates: estimates from U.S. national surveys, 2002. Spine 131(23):2724-2727

2. Hart LG, Deyo RA, Cherkin DC (1995) Physician office visits for low back pain. Frequency, clinical evaluation, and treatment patterns from a U.S. national survey. Spine 20:11-19
3. Carey TS, Evans AT, Hadler NM, Lieberman G, Kalsbeek WD, Jackman AM et al (1996) Acute severe low back pain. A population-based study of prevalence and care-seeking. Spine 21:339344

4. Pengel LH, Herbert RD, Maher CG, Refshauge KM (2003) Acute low back pain: systematic review of its prognosis. BMJ 327:323

5. Frymoyer JW, Cats-Baril WL (1991) An overview of the incidences and costs of low back pain. Orthop Clin North Am 22:263-271

6. Von Korff M, Saunders K (1996) The course of back pain in primary care. Spine 21:2833-2837

7. Woolf CJ, Bennett GJ, Doherty M, Dubner R, Kidd B, Koltzenburg M, Lipton R, Loeser JD, Payne R, Torebjork E (1998) Towards a mechanism-based classification of pain? Pain 77:227229

8. Baron R, Binder A (2004) How neuropathic is sciatica? The mixed pain concept. Orthopade 33:568-575

9. Freynhagen R, Baron R, Tölle T, Stemmler E, Gockel U, Stevens M, Maier C (2006) Screening of neuropathic pain components in patients with chronic back pain associated with nerve root compression: a prospective observational pilot study (MIPORT). Curr Med Res Opin 22(3):529-537

10. Freynhagen R, Rolke R, Baron R, Tölle TR, Rutjes AK, Schu S, Treede RD (2008) Pseudoradicular and radicular low-back pain-a disease continuum rather than different entities? Answers from quantitative sensory testing. Pain 135(1-2):65-74

11. Kaki AM, El-Yaski AZ, Youseif E (2005) Identifying neuropathic pain among patients with chronic low-back pain: use of the Leeds assessment of neuropathic symptoms and signs pain scale. Reg Anesth Pain Med 30(5):422.e1-422.e9

12. Finnerup NB, Otto M, McQuay HJ, Jensen TS, Sindrup SH (2005) Algorithm for neuropathic pain treatment: an evidence based proposal. Pain 118:289-305

13. Moskowitz MH (2003) Pharmacotherapy of neuropathic low back pain. Curr Pain Headache Rep 7:178-187

14. Cruccu G (2007) Treatment of painful neuropathy. Curr Opin Neurol 20:531-535

15. Gilron I, Orr E, Tu D, O’Neill JP, Zamora JE, Bell AC (2005) A placebo-controlled randomized clinical trial of perioperative administration of gabapentin, rofecoxib and their combination for spontaneous and movement-evoked pain after abdominal hysterectomy. Pain 113:191-200

16. Gilron I, Bailey JM, Tu D, Holden RR, Weaver DF, Houlden RL (2005) Morphine, gabapentin, or their combination for neuropathic pain. N Engl J Med 352(13):1324-1334

17. Haythornthwaite JA (2005) Clinical trials studying pharmacotherapy and psychological treatments alone and together. Neurology 65(12 Suppl 4):20-31

18. Parsa AA, Sprouse-Blum AS, Jackowe DJ, Lee M, Oyama J, Parsa FD (2008) Combined preoperative use of celecoxib and gabapentin in the management of postoperative pain. Aesth Plast Surg 19 [Epub ahead of print]

19. Pota V, Maisto M, Pace M, Iannotti M, Ruggiero E, Galdo E, Passavanti MA (2007) Association of buprenorphine TDS and pregabalin in the treatment of low back pain. Eur J Pain 11(1):83

20. Torrance N, Smith BH, Watson MC, Bennett MI (2007) Medication and treatment use in primary care patients with chronic pain of predominantly neuropathic origin. Fam Pract 24(5):481485

21. Lesser H, Sharma U, LaMoreaux L, Poole RM (2004) Pregabalin relieves symptoms of painful diabetic neuropathy. A randomized controlled trial. Neurology 63:2104-2110

22. Richter RW, Portenoy R, Sharma U, Lamoreaux L, Bockbrader H, Knapp LE (2005) Relief of painful diabetic peripheral neuropathy with Pregabalin: a randomized, placebo-controlled trial. J Pain 6(/4):253-260 
23. Vannier JL, Belkheyar Z, Oberlin C, Montravers P (2008) Prise en charge des douleurs neuropathiques des lesions traumatiques du plexus brachial chez l'adulte. A propos de 60 cas. Ann Fr Anesth Reanim 27(11):890-895

24. Meunier A, Lisander B, Good L (2007) Effects of celecoxib on blood loss, pain, and recovery of function after total knee replacement. A randomized placebo-controlled trial. Acta Orthop 78(5):661-667

25. Reuben SS, Buvenandran A, Katz B, Kroin JS (2008) Prospective randomized trial on the role of perioperative Celecoxib administration for total knee arthroplasty: improving clinical outcomes. Anesth Analg 106(/4):1258-1264

26. Singh G, Fort JG, Goldstein JL, Levy RA, Hanrahan PS, Bello AE, Andrade-Ortega L, Wallemark C, Agrawal NM, Eisen GM, Stenson WF (2006) Triadafilopoulos G; SUCCESS-I Investigators. Celecoxib versus naproxen and diclofenac in osteoarthritis patients: SUCCESS-I Study. Am J Med 119(3):255-266

27. The Bennett MI, SS LAN (2001) Pain scale: the Leeds assessment of neuropathic symptoms and signs. Pain 92(1-2):147-157

28. Pérez C, Gálvez R, Insausti J, Bennett M, Ruiz M, Rejas J (2006) Group for the study of Spanish validation of LANSS [Linguistic adaptation and Spanish validation of the LANSS (Leeds Assessment of Neuropathic Symptoms and Signs) scale for the diagnosis of neuropathic pain]. Med Clin (Barc) 127(13):485-491
29. Roelofs PD, Deyo RA, Koes BW, Scholten RJ, van Tulder MW (2008) Non-steroidal antiinflammatory drugs for low back pain. Cochrane Database Syst Rev 1:CD000396

30. Stacey BR, Swift JN (2006) Pregabalin for neuropathic pain based on recent clinical trials. Curr Pain Headache Rep 10(3):179-184

31. Arnold LM, Russell IJ, Diri EW, Duan WR, Young JP Jr, Sharma U, Martin SA, Barrett JA, Haig G (2008) A 14-week, randomized, double-blinded, placebo-controlled monotherapy trial of pregabalin in patients with fibromyalgia. J Pain 9(9):792-805

32. Mease PJ, Russell IJ, Arnold LM, Florian H, Young JP Jr, Martin SA, Sharma U (2008) A randomized, double-blind, placebocontrolled, phase III trial of pregabalin in the treatment of patients with fibromyalgia. J Rheumatol 35(3):502-514

33. Gatti A, Sabato AF, Occhioni R, Colini Baldeschi G, Reale C (2009) Controlled-release oxycodone and pregabalin in the treatment of neuropathic pain: results of a multicenter Italian study. Eur Neurol 61:129-137

34. Bennett MI, Attal N, Backonja MM, Baron R, Bouhassira D, Freynhagen R, Scholz J, Tolle TR, Wittchen H-U, Jensen TS (2007) Using screening tools to identify neuropathic pain. Pain 127:199-203 